\title{
Experimental Evaluation of the Shadowing of a Planar Antenna Caused by a Quadcopter Frame
}

\author{
Ibrahim Heydarov* (Azerbaijan Airlines, Baku, Azerbaijan), \\ Deniss Brodnevs (Lecturer, Riga Technical University, Riga, Latvia)
}

\begin{abstract}
The use of mobile data transfer can significantly increase the range of the remote-controlled operation of multirotor aerial vehicles. The planar antennas of ready-to-use 3G/LTE cellular communication dongles provide a low-cost and lightweight communication solution. In this paper, antenna shadowing caused by a quadcopter frame is experimentally investigated. The communication module is a 3G/LTE "Huawei $3372 \mathrm{~h}$ " dongle with two planar built-in antennas and a receiver diversity function. The quadcopter frame is a widely used "F450" with Nylon arms and a PCB centre. It has been found that in order to minimize the antenna shadowing effect, planar antennas should be installed at the bottom of the frame, in parallel with the frame, with an air gap not less than the distance to the outer boundary of the reactive Near Field (NF).
\end{abstract}

Keywords - 3G; 4G; Antenna pattern; Antenna shadowing; Copter; LTE; Mobile data transfer; Multirotor; Planar antenna; Quadrotor; RPAS; UAV.

\section{INTRODUCTION}

Unmanned Aerial Systems (UAS) (in particular, Remotely Piloted Aircraft Systems (RPAS)) require a wireless communication channel for performing remote-controlled operations. Typically, small size Remote Piloted Aircrafts (RPA) are equipped with several wireless transmit-receivers for various purposes: Remote-Control (RC), telemetry, as well as First Person View (FPV). Note that in International Civil Aviation Organization (ICAO) terminology, these channels are combined into one channel called the Command and Control Link (C2 Link) [1].

The wireless RC link should provide a data channel with a low latency (near to real-time) and low data rate (several kilobytes per second). In contrast, the wireless telemetry link has no real-time requirements, while the data transfer rate is higher (several tens of kilobits per second [2], [3]). Since both above-mentioned channels do not require high data rates, they can operate with a slow modulation scheme, therefore, with a high Fade Margin (FM). FM is the difference between the nominal receive level and the receiver threshold level (the minimum signal required for the demodulator to operate with a certain error rate). Since FM is usually high for these channels, the small scale fading usually is not considered.

The wireless FPV link should provide a high data rate along with a low latency (typically several thousands of kilobits per second with a latency of less than $150 \mathrm{~ms}$ [4], [5]). The situation is further exacerbated by the fact that the power of the transmitter is limited by the power consumption of the transmitter and the maximum RF output power limits [6]. Consequently, FPV wireless links typically operate with highorder modulation, and the FM is small. In this case, small scale fading should be considered in the wireless link budget.

The wireless link budget depends on the antenna pattern. The antenna pattern may be significantly distorted due to a Visual Line of Sight (VLOS) obstruction caused by an RPA frame. Since a typical RPA has high manoeuvrability, the task of choosing the optimal antenna location becomes more complicated. Typically, a communication antenna should be installed in or near the centre of the frame due to the limited sizes of RPA frame. In this case, the frame shadowing on the antenna pattern occurs and the resulting antenna pattern becomes distorted.

There are several scientific papers available devoted to the effect of frame shadowing. In [7], [8], the authors used NASA's S-3B Viking airplane with two receiving L-band omnidirectional antennas and two receiving $\mathrm{C}$-band omni-directional antennas, mounted on the bottom of the fuselage. The distance between the antennas was $1.8 \mathrm{~m}$. The flight speed was in the range from $70 \mathrm{~m} / \mathrm{s}$ to $150 \mathrm{~m} / \mathrm{s}$. The transmitting antennas were installed at a height of $20 \mathrm{~m}$ above the ground. They found that during manoeuvring, the maximum shadowing in C-band was $28.69 \mathrm{~dB}$ and $32.66 \mathrm{~dB}$ in the L-band, respectively. The authors suggest and mathematically prove that the distance increased between the antennas by more than $1.8 \mathrm{~m}$ will help to reduce the impact of antenna shadowing [9]. In [10], the authors used Learjet-35A, which was equipped with a C-band transmitter and an omni-directional antenna, operating with an Effective Radiated Power (ERP) of $40 \mathrm{dBm}$. The ground antennas were directional. They found that shadowing could be up to $9.5 \mathrm{~dB}$ at $5.7 \mathrm{GHz}$ for a linear flight, and up to $28 \mathrm{~dB}$ for a circular flight with a roll of $27 \mathrm{deg}$. In [11], the authors experimentally investigated the air-to-ground link in C-band above the sea surface and found that the standard deviation of $0.97 \mathrm{~dB}$ of the received signal was caused by the antenna shadowing during linear flight. Unfortunately, the authors did not specify the model of the aircraft. All other papers are related to a human-

\footnotetext{
* Corresponding author.

E-mail: ibo.heyderov94@mail.ru
} 
shadowing effect imposed on the aerial of mobile user equipment, e.g., [12]-[16].

The above review confirms that the problem of antenna shadowing caused by the airframe exists and is vital. However, only a few papers addressing the problem can be found. Finally, in [17], the authors also stated the need for additional research in the field of antenna shadowing caused by the UAV frame.

In this paper, we will experimentally investigate the shadowing effect caused by the popular F450 quadrotor frame on the antenna pattern of a planar omnidirectional antenna. The frame brackets are made of nylon, chemically reinforced with $30 \%$ glass fibre and with the content of thermoplastic caoutchouc. The frame body centre is made of two PCB plates surrounded by conductive loops made from copper. A planar omni-directional antenna will be attached from the bottom to the centre of the frame. To eliminate the multipath effect caused by reflections from the ground surface, the communication module is equipped with two receiving antennas, thus providing receiver diversity.

\section{METHODS}

In the following measurements, the Huawei 3372h [18] will be used as a communication module. The Huawei $3372 \mathrm{~h}$ is a $2 \mathrm{G} / 3 \mathrm{G} / \mathrm{LTE}$ USB dongle. The communication module is equipped with two omni-directional multiband planar antennas. The multiband antennas can operate on the $800 \mathrm{MHz}, 850 \mathrm{MHz}$, $900 \mathrm{MHz}, 1.8 \mathrm{GHz}, 1.9 \mathrm{GHz}, 2.1 \mathrm{GHz}$ and 2.6 GHz bands. The communication module has two integrated planar antennas that are used only for receiver diversity. The Huawei $3372 \mathrm{~h}$ is an LTE Cat. 4 device; therefore, it does not support Carrier Aggregation (CA) (simultaneous usage of multiple carriers) and the second antenna is used only for the receiver diversity. The receiver diversity minimizes the effect of multipath (small-scale fading) caused by reflections from the ground as well as all other surfaces of the surrounding objects.

The resulting antenna pattern of the communication module (considering receiver diversity) was obtained experimentally. The communication module automatically returns the parameters of the received (downlink) signal, such as Received Signal Strength Indicator (RSSI, dBm) in $2 \mathrm{G}$ mode; RSSI, Received Signal Code Power (RSCP, dBm) and carrier-tointerference ratio $\left(E_{\mathrm{c}} / I_{\mathrm{o}}, \mathrm{dB}\right)$ in $3 \mathrm{G}$ mode; RSSI, Reference Signal Received Power (RSRP, $\mathrm{dBm}$ ) and Signal to Interference plus Noise Ratio (SINR, dB) and Reference Signal Received Quality (RSRQ, dB) in LTE (4G) mode. Unfortunately, the RSSI indicates the total power level received from all Base Stations (BSs); whereas the RSCP and $E_{\mathrm{c}} / I_{\mathrm{o}}$ (in $3 \mathrm{G}$ ) or RSRP and SINR (in LTE) are reported with respect to a selected BS. Since there are a lot of BSs around the communication module, the communication module has many connection options. Since the choice of a BS is performed automatically (the "celllock" function is not implemented in Huawei $3372 \mathrm{~h}$ ), it is not possible to lock the communication module on a specific BS. This allows the communication module to select various BSs during the experiment, which makes the results incomparable to each other.
To overcome the problem mentioned above, it is possible to make a search for all available BSs. The communication module is able to search for BSs of all cellular operators irrespective of the installed SIM card. The search result contains the Cell ID (CID) of BS, as well as their power in $\mathrm{dBm}$ received by the receiver. Therefore, it is possible to indicate the level of the received power for a selected BS. Since in $3 G$ and LTE (4G) BSs do not adjust their output power, any change in the level of received power is caused by the receiving antenna pattern.

During the experiments, a tripod with the height of $1.6 \mathrm{~m}$ has been used. In order to reduce the impact of the tripod, the communication module was attached to a piece of plastic foam. In turn, the angles of the vertical and horizontal planes could be adjusted. The plastic foam has two seats (one for the rotation in vertical and the second one for the rotation in horizontal plane) that are aligned to make the rotation axis immovable. The measurements were carried out in increment of 45 deg both in the vertical and horizontal planes. Three measurements were performed at each position and then the values were averaged.

To reduce the impact of the environment, the experiment has been performed in the open field with flat surface of Spilve meadows. The Huawei $3372 \mathrm{~h}$ is able to perform the search only for the $2 \mathrm{G}$ and $3 \mathrm{G}$ BSs. In Riga, all the $3 \mathrm{G}$ BSs are operating on B1 $(2100 \mathrm{MHz})$ band. Therefore, during the experiment, only B1 band of $3 \mathrm{G}(2100 \mathrm{MHz})$ can be tested. The received signal level will be displayed for the $3 \mathrm{G}$ BS of Bite-LV, $\mathrm{LAC}=\mathrm{a} 4, \mathrm{CID}=\mathrm{d} 66 \mathrm{~d}$, whereas all other BSs will be ignored. This BS operates on $2.1 \mathrm{GHz}$ band with a fixed bandwidth of $5 \mathrm{MHz}$ and is located at the edge of the meadow (see Fig. 2), at a height of 28 meters with respect to the meadow surface.

At first, the antenna pattern was obtained for the stand-alone communication module. Further, the communication module was attached from the bottom on the "F450" quadcopter frame in parallel with the PCB centre of the frame. Further, the effect of various gap sizes between the communication module and the frame was experimentally evaluated. The choice of the value of the gap is another source of concern. First of all, it is necessary to note that some parts made of conductive materials located in the reactive Near Field (NF) of the antenna become part of the antenna system, therefore, would distort the properties of the antenna. Since the planar inverted-F antenna (PIFA) antenna of the communication module is the electromagnetically short antenna (its size is smaller than half of the wavelength), the size of the antenna will not be taken into account and the outer boundary of the reactive near field region can be found by Eq. (1). Considering frequency $f=2100 \mathrm{MHz}$, the outer boundary $r_{\mathrm{RNF}}$ of the reactive NF region is on $23 \mathrm{~mm}$ :

$$
r_{\mathrm{RNF}}=\frac{\lambda}{2 \pi}=\frac{0.143}{2 \pi}=22.75 \mathrm{~mm} .
$$

Further, the outer boundary of the radiated NF region can be found by Eq. (2). Considering $f=2100 \mathrm{MHz}$, the outer boundary $r_{\mathrm{NF}}$ of the radiated NF region is on $143 \mathrm{~mm}$ :

$$
r_{\mathrm{NF}}=\lambda=142.9 \mathrm{~mm} .
$$




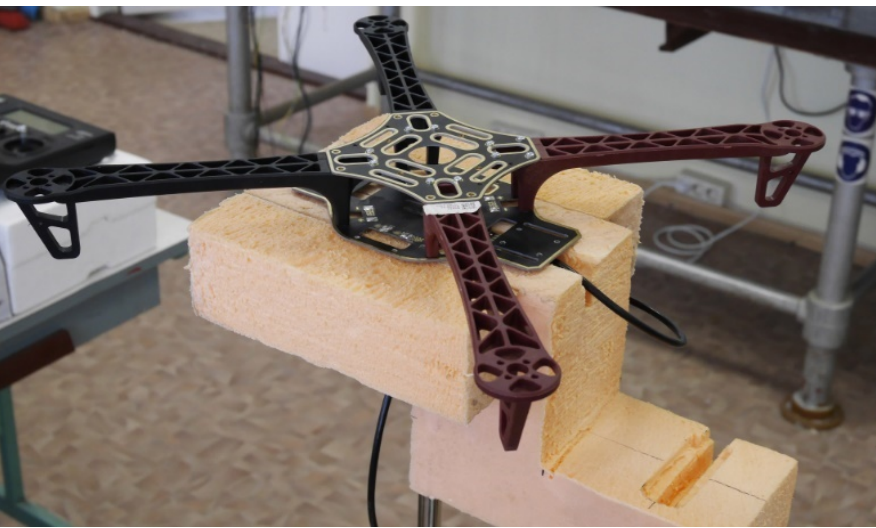

Fig. 1. Quadcopter's "F450" frame with the attached communication module on its bottom, installed on the tripod caption.

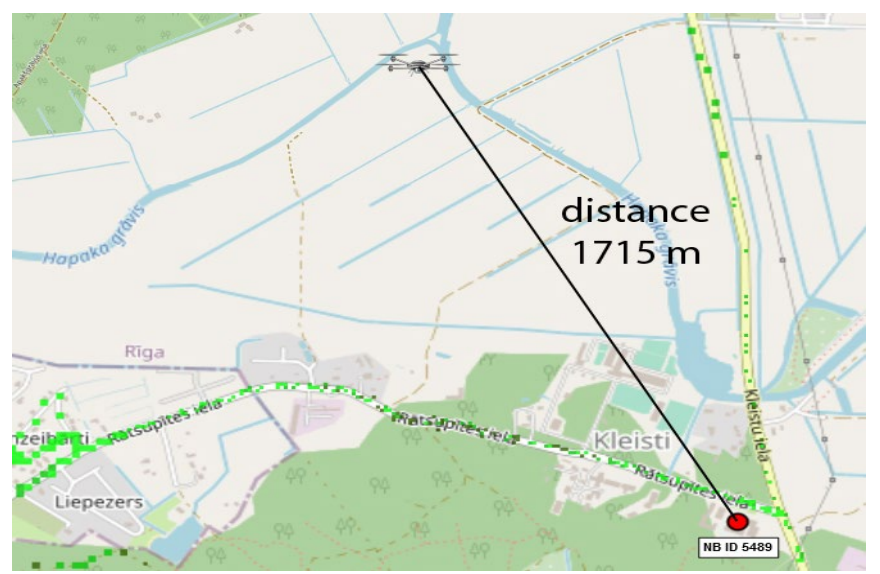

Fig. 2. The locations of the experimental setup as well as of the selected BS.

Finally, the value of the inner boundary of the Far Field (FF) region can be found by Eq. (3). Considering $f=2100 \mathrm{MHz}$, the inner boundary $r_{\mathrm{FF}}$ of the FF region is on $1286 \mathrm{~mm}$ :

$$
r_{\mathrm{FF}}=2 \lambda=285.7 \mathrm{~mm} \text {. }
$$

It is necessary to find the FF region if the field measurements should be performed. Since the module acts as a measurement equipment by itself and only received power is measured, both the FF boundary and the NF-FF transition zone can be ignored. Thus, there is only one restriction with regard to the antenna system that should be considered: the reactive NF should be clean from any conductive obstacles, otherwise the antenna properties will be changed. This requirement forces us to put the communication module with the gap of at least $23 \mathrm{~mm}$ from the antenna.

However, sometimes such a requirement cannot be met due to space restrictions on small RPA. In this case, the shadowing effect of the antenna will be aggravated by the change of the antenna parameters. Such effects cannot be easily foreseen, thus, will be experimentally evaluated. During the experiment, the communication module was attached at the bottom, in the centre of the PCB frame, in four positions:

- tight (zero clearance between the enclosure of the communication module and the bottom of the frame results in a $3 \mathrm{~mm}$ gap between the antennas and the bottom of the PCB frame);
- with a gap of $10 \mathrm{~mm}$ between the enclosure of the communication module and the bottom of the frame (a $13 \mathrm{~mm}$ gap between the antennas and the bottom of the PCB frame);

- with a gap of $20 \mathrm{~mm}$ between the enclosure of the communication module and the bottom of the frame (a $23 \mathrm{~mm}$ gap between the antennas and the bottom of the PCB frame, thus on the outer boundary of the reactive NF);

- with a gap of $30 \mathrm{~mm}$ between the enclosure of the communication module and the bottom of the frame (thus, a $33 \mathrm{~mm}$ gap between the antennas and the bottom of the PCB frame).

The longitudinal axis of the communication module was aligned with the longitudinal axis of the frame. As shown in Fig. 3, at 0 -degree orientation in the horizontal plane the longitudinal axes of the drone and the communication module were directed to the BS.

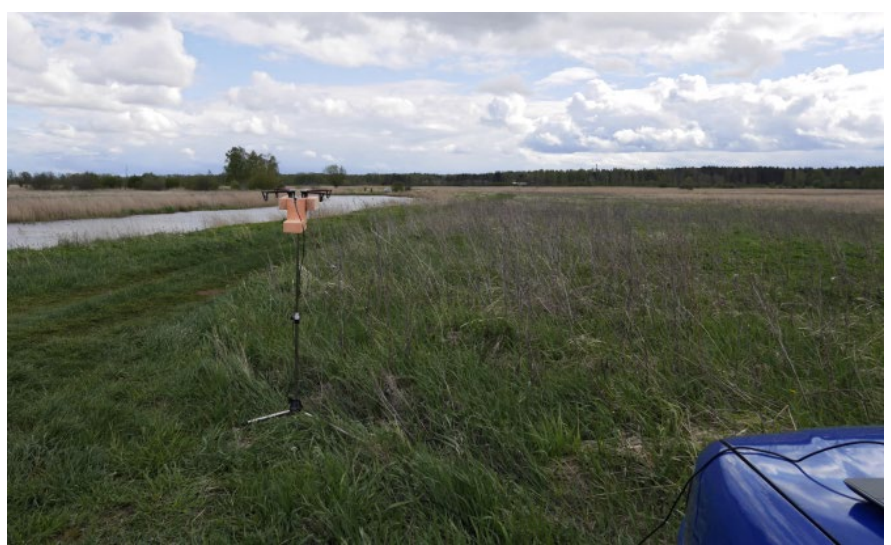

Fig. 3. At 0-degree orientation the longitudinal axes of the drone and the communication module were directed to the BS.

\section{RESULTS}

First, it was necessary to obtain the antenna pattern of the stand-alone communication module. The module was attached to the piece of plastic foam, installed on the tripod and rotated in a horizontal plane in increments of 45 degrees. In the 0 deg position, the longitudinal axis of the communication module was aligned with the $3 \mathrm{G}$ BS of Bite-LV, $L A C=a 4, C I D=d 66 d$ as shown in Figs. 2 and 3. To reduce the measurement error, the results were averaged over the three measurements that were taken in each position. Further, in order to obtain a variation of the antenna pattern (relative gain), all the power levels of the received signal were subtracted from the averaged power obtained during this experiment. Therefore, if the obtained power level from the BS is higher than the average power, the relative gain will be positive and vice versa. The experimental results are shown in Table I. The average level of the received signal of the stand-alone antenna is $-55.1 \mathrm{dBm}$ and the variance is $9.14 \mathrm{~dB}^{2}$.

Further, the communication module was mounted on the centre at the bottom of the "F450" PCB frame. First, the communication module was attached tightly (without any gap between the frame and the enclosure of the communication module, thus with the gap of $3 \mathrm{~mm}$ between the antennas and 
the bottom of the frame). Next, the communication module was attached with a gap of $10 \mathrm{~mm}$ between the bottom of the frame and the communication module (thus with the gap of $13 \mathrm{~mm}$ between the antennas and the bottom of the frame). Further, the communication module was attached with a gap of $20 \mathrm{~mm}$ between the bottom of the frame and the communication module (thus with the gap of $23 \mathrm{~mm}$ between the antennas and the bottom of the frame). Finally, the communication module was attached with a gap of $30 \mathrm{~mm}$ between the bottom of the frame and the communication module (thus with the gap of $33 \mathrm{~mm}$ between the antennas and the bottom of the frame). Now, the shadowing effect of the antenna could be found. For this purpose, the relative gain of the antenna was calculated as the difference between the level of the received signal in the given configuration and the average signal level of the standalone communication module in the horizontal plane. The experimental results are shown in Table II. The relative gain is shown in Fig. 4.

The average level of the signal received from a tightly attached antenna is $-59.29 \mathrm{dBm}$ (by $4.21 \mathrm{~dB}$ less than for a stand-alone antenna); $-58.63 \mathrm{dBm}$ with the $10 \mathrm{~mm}$ gap between the communication module and the frame (by $3.55 \mathrm{~dB}$ less than for a stand-alone antenna); $-57.41 \mathrm{dBm}$ if the communication module is installed with the gap of $20 \mathrm{~mm}$ (by $2.34 \mathrm{~dB}$ less than for a stand-alone antenna); $-56.10 \mathrm{dBm}$ if the communication module is installed with the gap of $30 \mathrm{~mm}$ (by $1.025 \mathrm{~dB}$ less than for a stand-alone antenna). The gain variance of a tightly mounted antenna is $25.58 \mathrm{~dB}^{2} ; 37.08 \mathrm{~dB}^{2}$ if the communication module is installed with the gap of $10 \mathrm{~mm}, 39.44 \mathrm{~dB}^{2}$ if the communication module is installed with the gap of $20 \mathrm{~mm}$ and $29.53 \mathrm{~dB}^{2}$ if the communication module is installed with the gap of $30 \mathrm{~mm}$.

TABLE I

Received Signal Level of The Stand-Alone Horizontally Placed Communication Module, Depending on the ORIEntation of the COMMUNiCATION MOdule in Horizontal Plane

\begin{tabular}{|c|c|c|c|c|c|c|}
\hline \multirow[b]{2}{*}{ Orientation, deg } & \multicolumn{5}{|c|}{ Received power level, $\mathrm{dBm}$} & \multirow[b]{2}{*}{$\begin{array}{l}\text { Relative gain of } \\
\text { the antenna, dB }\end{array}$} \\
\hline & $1^{\text {st }}$ measurement & $2^{\text {nd }}$ measurement & $3^{\text {rd }}$ measurement & Averaged & $\begin{array}{l}\text { Averaged signal } \\
\text { level during the } \\
\text { experiment }\end{array}$ & \\
\hline $\mathbf{0}$ & -59 & -60 & -59 & -59.3 & \multirow{8}{*}{-55.075} & -4.225 \\
\hline 45 & -57 & -57 & -58 & -57.3 & & -2.225 \\
\hline 90 & -58 & -58 & -57 & -57.7 & & -2.625 \\
\hline 135 & -57 & -57 & -57 & -57 & & -1.925 \\
\hline 180 & -52 & -53 & -52 & -52.3 & & 2.775 \\
\hline 225 & -53 & -52 & -53 & -52.7 & & 2.375 \\
\hline 270 & -55 & -54 & -54 & -54.3 & & 0.775 \\
\hline 315 & -50 & -50 & -50 & -50 & & 5.075 \\
\hline
\end{tabular}

TABLE II

Received Signal Level of the COMmunication Module, Depending On the Orientation of the Communication Module in HoRizontal Plane

\begin{tabular}{|c|c|c|c|c|c|}
\hline \multirow[b]{2}{*}{$\begin{array}{c}\text { Orientation, } \\
\text { deg }\end{array}$} & \multicolumn{5}{|c|}{ Relative gain of the antenna, $\mathrm{dB}$} \\
\hline & $\begin{array}{l}\text { Stand-alone } \\
\text { communication } \\
\text { module }\end{array}$ & $\begin{array}{l}\text { Communication } \\
\text { module is attached } \\
\text { without the gap }\end{array}$ & $\begin{array}{l}\text { Communication module } \\
\text { is attached with the gap } \\
\text { of } 10 \mathrm{~mm}\end{array}$ & $\begin{array}{l}\text { Communication module } \\
\text { is attached with the gap } \\
\text { of } 20 \mathrm{~mm}\end{array}$ & $\begin{array}{l}\text { Communication module } \\
\text { is attached with the gap } \\
\text { of } 30 \mathrm{~mm}\end{array}$ \\
\hline $\mathbf{0}$ & -4.225 & 0.075 & -9.925 & -13.225 & -5.925 \\
\hline 45 & -2.225 & -3.925 & -3.925 & -7.225 & -8.925 \\
\hline 90 & -2.625 & -15.925 & -6.625 & -6.625 & -5.625 \\
\hline 135 & -1.925 & 0.075 & 2.075 & 3.075 & 2.775 \\
\hline 180 & 2.775 & 0.075 & 3.075 & 3.375 & 5.375 \\
\hline 225 & 2.375 & -1.925 & 0.075 & 3.075 & 3.375 \\
\hline 270 & 0.775 & -6.225 & -14.925 & -5.925 & -4.625 \\
\hline 315 & 5.075 & -5.925 & 1.775 & 4.775 & 5.375 \\
\hline
\end{tabular}

TABLE III

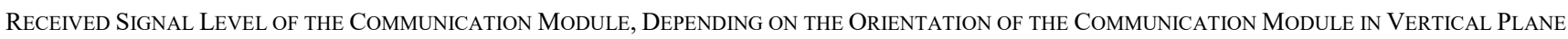

\begin{tabular}{|c|c|c|c|c|c|}
\hline \multirow[b]{2}{*}{$\begin{array}{c}\text { Orientation, } \\
\text { deg }\end{array}$} & \multicolumn{5}{|c|}{ Relative gain of the antenna, $\mathrm{dB}$} \\
\hline & $\begin{array}{l}\text { Stand-alone } \\
\text { communication } \\
\text { module }\end{array}$ & $\begin{array}{l}\text { Communication } \\
\text { module is attached } \\
\text { without the gap }\end{array}$ & $\begin{array}{l}\text { Communication module } \\
\text { is attached with the gap } \\
\text { of } 10 \mathrm{~mm}\end{array}$ & $\begin{array}{l}\text { Communication module } \\
\text { is attached with the gap } \\
\text { of } 20 \mathrm{~mm}\end{array}$ & $\begin{array}{l}\text { Communication module } \\
\text { is attached with the gap } \\
\text { of } 30 \mathrm{~mm}\end{array}$ \\
\hline-90 & 3.7 & -13 & -6.0 & -5.0 & -6.0 \\
\hline 45 & 1.0 & -17 & -8.3 & -6.0 & -6.0 \\
\hline $\mathbf{0}$ & -6.7 & -15 & -4.3 & 0.3 & 1.0 \\
\hline 45 & -1.0 & -6.3 & -3.0 & -1.0 & 0 \\
\hline 90 & 3.0 & -17 & 0 & -1.0 & 0 \\
\hline
\end{tabular}


Next, it is necessary to obtain the antenna pattern of the stand-alone communication module in the vertical plane. The module was attached to the piece of plastic foam mounted on the tripod and rotated in the vertical plane in increments of 45 degrees. The orientation is shown in Fig. 5. During this experiment, the longitudinal axis of the communication module was directed to the BS ( 0 deg orientation in the horizontal plane). Therefore, the communication module becomes shadowed by two PCB boards of the frame at $-90 \mathrm{deg}$, and $-45 \mathrm{deg}$ positions, whereas at $45 \mathrm{deg}$ and $90 \mathrm{deg}$ positions the PCB boards of the frame may act as a mirror or interact with the antenna system if the distance is less that the outer boundary of the reactive NF $r_{\text {RNF. }}$.

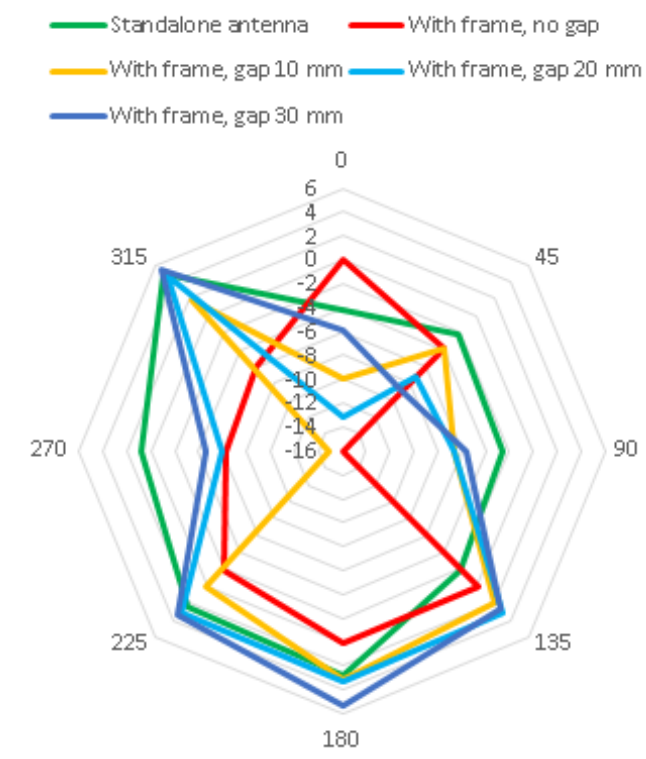

Fig. 4. Relative antenna gain depending on the configuration and orientation of the communication module and frame in horizontal plane.

To eliminate the measurement error caused by the communication module, the results were averaged over the three measurements that had been taken at each position. Further, in order to obtain a variation in the antenna radiation pattern (relative gain), all power levels of the received signal were subtracted from the average power obtained during this experiment. Therefore, if the received power level from a BS is higher than the average power, the relative gain will be positive. The experimental results are shown in Table III. The relative gain is shown in Fig. 5.

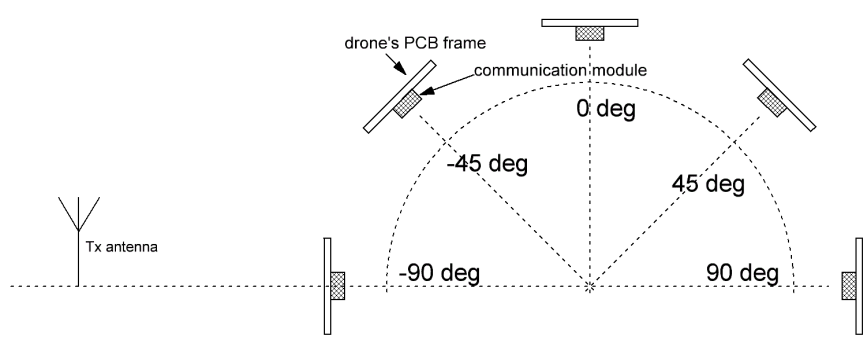

Fig. 5. Illustration of the orientation of the frame and communication module in the vertical plane.

The average level of the received signal from a standalone antenna is $-53 \mathrm{dBm}$. The average level of the received signal from a tightly attached communication module is $-66.7 \mathrm{dBm}$ (by $13.7 \mathrm{~dB}$ less than for a stand-alone communication module); $-57.3 \mathrm{dBm}$ with the $10 \mathrm{~mm}$ gap between the communication module and the frame (by $4.32 \mathrm{~dB}$ less than for a stand-alone communication module); $-55.4 \mathrm{dBm}$ if the communication module is installed with the gap of $20 \mathrm{~mm}$ (by $2.54 \mathrm{~dB}$ less than for a stand-alone antenna); $-55.2 \mathrm{dBm}$ if the communication module is installed with the gap of $30 \mathrm{~mm}$ (by $1 \mathrm{~dB}$ less than for a stand-alone antenna). The gain variance of the stand-alone communication module is $13.9 \mathrm{~dB}^{2} ; 15.7 \mathrm{~dB}^{2}$ if the communication module is installed tightly to the frame; $7.81 \mathrm{~dB}^{2}$ if the communication module is installed with the gap of $10 \mathrm{~mm}, 6.17 \mathrm{~dB}^{2}$ if the communication module is installed with the gap of $20 \mathrm{~mm}$ and $9.76 \mathrm{~dB}^{2}$ if the communication module is installed with the gap of $30 \mathrm{~mm}$

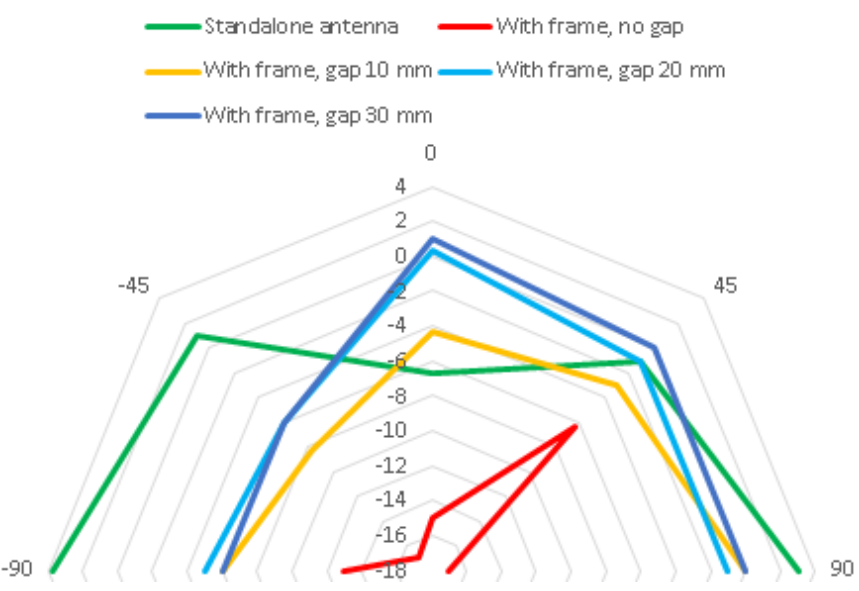

Fig. 6. Illustration of the orientation of the frame and communication module in the vertical plane.

\section{DISCUSSION}

In this paper, the antenna pattern of a Huawei $3372 \mathrm{~h}$ module was experimentally obtained on the $2.1 \mathrm{GHz}$ frequency band. The Huawei $3372 \mathrm{~h}$ is equipped with two planar (PIFA) antennas and provides receiver diversity to minimize the multipath effect. Ignoring the multipath effects (which should be partially compensated by the receiver diversity) it was found that the resulting antenna pattern of the communication module could be considered omnidirectional and had a variation of the antenna pattern in horizontal plane of $9.14 \mathrm{~dB}^{2}$ (about $\pm 4.6 \mathrm{~dB}$ ) and in vertical plane of $13.9 \mathrm{~dB}^{2}$ (about $\pm 5.2 \mathrm{~dB}$ ). From the data experimentally obtained in the vertical plane, the module has two gain maximums of approx. $3 \mathrm{~dB}$ in the plane perpendicular to the plane of the planar antenna. Therefore, terrestrial users should place the communication module in the plane perpendicular to the ground surface. However, since the RPA are typically flying above the BS, the communication module should be placed in parallel with the ground surface.

Further, the communication module was installed on the "F450" quadrotor frame. The central part of the frame is made of two PCB plates surrounded by metal traces. The outer boundary of the reactive NF on the $2.1 \mathrm{GHz}$ frequency is on $23 \mathrm{~mm}$. The distance of the antennas to the plastic enclosure of 
the communication module is $3 \mathrm{~mm}$. It was found that if the communication module was installed tightly to the frame ( $3 \mathrm{~mm}$ gap between the antennas and the frame) as well as with the gap of $10 \mathrm{~mm}$ (13 mm gap between the antennas and the frame), the antenna pattern would become distorted and the average received power would drop significantly both in vertical and horizontal planes. In a horizontal plane, there are no significant differences in the gain if the gap between the communication module and the frame is increased by more than $20 \mathrm{~mm}$ (thus the gap between the antennas and the frame is more than $23 \mathrm{~mm}$ ). Similar situation is in a vertical plane: there are no significant differences in the gain if the gap between the communication module and the frame is increased by more than $20 \mathrm{~mm}$ and the module is not shadowed by the frame (positions $0 \mathrm{deg}, 45 \mathrm{deg}$ and $90 \mathrm{deg}$ ), whereas smaller gaps result in the drop of the gain (by up to $-19 \mathrm{~dB}$ in a tight position) even of the frame does not cause the shadowing of the antenna.

The maximum shadowing caused by two PCB plates of the frame can be found from the experiment in the vertical plane: in $-90 \mathrm{deg}$ position, the stand-alone antenna provides a relative gain of $3.7 \mathrm{~dB}$, whereas for the shadowed communication module (position $90 \mathrm{deg}$ ) when the gap is $20 \mathrm{~mm}$ and more (antenna reactive NF is free from interfering objects), when the radio waves mainly pass through the frame, the relative gain is $-5 \mathrm{~dB}$, resulting in approx. $9 \mathrm{~dB}$ shadowing caused by the frame.

\section{CONCLUSION}

It can be concluded that for terrestrial users a cellular mobile communication module (or stand-alone PIFA antenna) should be installed in the plane perpendicular to the ground surface. On RPA, a cellular mobile communication module (or stand-alone PIFA antenna) should be installed below a frame (to ensure LOS visibility at high altitudes with cellular towers (BS)); otherwise, additional losses will occur (of approx. $9 \mathrm{~dB}$ in case of frame centre made of PCB). The communication module should be installed with a gap, which is greater than the size of the reactive NF of the antenna (in case of $2.1 \mathrm{GHz}$ frequency the gap should be greater than $23 \mathrm{~mm}$, where the PIFA antenna is considered a "point antenna" (electromagnetically short antenna)). The distance to the outer boundary to the reactive NF can be determined by (1); the orientation of the communication module with respect to the surface of the RPA frame should be in parallel; the orientation of the communication module with respect to the longitudinal axis of the RPA frame can be various (has no impact).

\section{REFERENCES}

[1] International Civil Aviation Organization (ICAO), "Remotely Piloted Aircraft System (RPAS) Concept of Operations (CONOPS) for International IFR,” p. 22, 2014.

[2] National Instruments, "3GPP Release 15 Overview," IEEE Commun. Soc. White Pap., 2018.

[3] S. D. Muruganathan, X. Lin, H.-L. Maattanen, Z. Zou, W. A. Hapsari, and S. Yasukawa, "An Overview of 3GPP Release-15 Study on Enhanced LTE Support for Connected Drones," pp. 1-7, 2018.

[4] ITU, "ITU-T G.1010 End-User Multimedia QoS Categories Series G: Transmission Systems and Media, Digital Systems and Networks Quality of Service and Performance," 2001.

[5] ITU, "ITU-T Y.1541 Network performance objectives for IP-based services," 2011.

[6] ITU, "ITU-R SM.2153-7 Technical and operating parameters and spectrum use for short-range radiocommunication devices," ITU - Spectr. Manag., vol. 1, 2019.

[7] D. W. Matolak and R. Sun, "Air-Ground Channel Characterization for Unmanned Aircraft Systems-Part I: Methods, Measurements, and Models for Over-Water Settings," IEEE Trans. Veh. Technol., vol. 66, no. 1, 2017. https://doi.org/10.1109/TVT.2016.2530306

[8] R. Sun and D. W. Matolak, "Air-Ground Channel Characterization for Unmanned Aircraft Systems Part II: Hilly and Mountainous Settings," IEEE Trans. Veh. Technol., vol. 66, no. 3, 2017. https://doi.org/10.1109/TVT.2016.2585504

[9] D. W. Matolak, H. Jamal, and R. Sun, "Spatial and frequency correlations in two-ray air-ground SIMO channels," in IEEE International Conference on Communications, 2017. https://doi.org/10.1109/ICC.2017.7996954

[10] Y. S. Meng and Y. H. Lee, "Study of shadowing effect by aircraft maneuvering for air-to-ground communication," AEU - Int. J. Electron. Commun., vol. 66, no. 1, 2012. https://doi.org/10.1016/i.aeue.2011.04.006

[11] Y. S. Meng and Y. H. Lee, "Measurements and characterizations of airto-ground channel over sea surface at C-band with low airborne altitudes," IEEE Trans. Veh. Technol., vol. 60, no. 4, 2011. https://doi.org/10.1109/TVT.2011.2136364

[12] M. Heino, C. Icheln, and K. Haneda, "Self-user shadowing effects of millimeter-wave mobile phone antennas in a browsing mode," in 13th European Conference on Antennas and Propagation, EuCAP 2019, 2019.

[13] I. Syrytsin, S. Zhang, G. F. Pedersen, K. Zhao, T. Bolin, and Z. Ying, "Statistical Investigation of the User Effects on Mobile Terminal Antennas for 5G Applications," IEEE Trans. Antennas Propag., vol. 65, no. 12, 2017. https://doi.org/10.1109/TAP.2017.2681701

[14] K. Zhao et al., "Channel Characteristics and User Body Effects in an Outdoor Urban Scenario at 15 and $28 \mathrm{GHz}$," IEEE Trans. Antennas Propag., vol. 65, no. 12, 2017. https://doi.org/10.1109/TAP.2017.2740959

[15] S. L. Cotton, A. McKernan, A. J. Ali, and W. G. Scanlon, "An experimental study on the impact of human body shadowing in off-body communications channels at $2.45 \mathrm{GHz}$," in Proceedings of the 5th European Conference on Antennas and Propagation, EUCAP 2011, 2011.

[16] T. V. Nguyen, E. Masry, and L. B. Milstein, "Channel model and performance analysis of QAM multiple antenna systems at $60-\mathrm{GHz}$ in the presence of human activity," in GLOBECOM - IEEE Global Telecommunications Conference, 2011 https://doi.org/10.1109/GLOCOM.2011.6134425

[17] A. A. Khuwaja, Y. Chen, N. Zhao, M. S. Alouini, and P. Dobbins, "A survey of channel modeling for uav communications," IEEE Commun. Surv. Tutorials, 2018. https://doi.org/10.1109/COMST.2018.2856587

[18] HUAWEI, "HUAWEI Dongles E3372h." [Online]. Available: $\mathrm{http}: / /$ consumer.huawei.com/en/mobile-broadband/dongles/techspecs/e3372.htm. [Accessed: 28-Sep-2016]. 


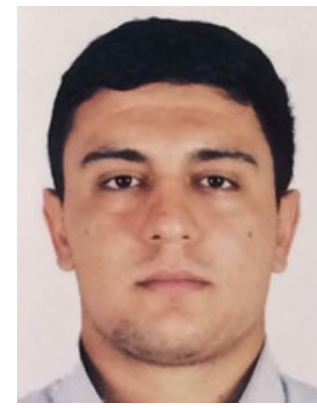

Ibrahim Heydarov in 2016 graduated from National Aviation Academy and earned bachelor's degree in Aerospace Engineering- an Air Traffic controller. From 2017 has been studying master's degree in Aviation TransportMechanical engineering at Riga Technical University.

To date, he is a self-employed person in Azerbaijan. Experience in AZAL (Azerbaijan Airlines) at the Air Traffic Control center in 3 consecutive summers from 2012 to 2016. His current research interests include air traffic E-mail: ibo.heyderov94@mail.ru

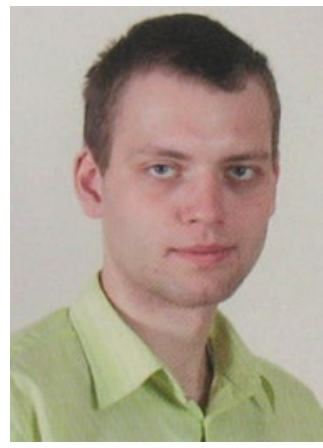

Deniss Brodnevs received the M. Sc. Eng. and B. Sc. Eng. degrees in Aviation transport from Riga Technical University (RTU), Institute of Aeronautics (AERTI) in 2013 and 2011 respectively.

To date, he is a lecturer in the AERTI of RTU, in Riga, Latvia. His previous job experience is electronic engineer in Aircraft Structures Fatigue and Wear Testing Center (Aviatest) and a computer system engineer of oil/gas tanker and refrigerator vessels of Latvian Shipping Company (LSC). His current research interests include wireless network development for small remotely piloted aircraft systems (RPAS).

E-mail: deniss.brodnevs@rtu.lv

ORCID iD: https://orcid.org/0000-0003-3296-187X 